Revue

Revue de l'histoire des religions

de Ihistoire des religions

1 | 2014

Varia

\title{
Daniela Sarasella, Cattolici a sinistra. Dal modernismo ai giorni nostri
}

Rome-Bari, Laterza («Quadrante Laterza », 178), 2011

\section{Giacomo Losito}

\section{(2) OpenEdition}

Journals

Édition électronique

URL : http://journals.openedition.org/rhr/8236

DOI : $10.4000 /$ rhr.8236

ISSN : 2105-2573

Éditeur

Armand Colin

Édition imprimée

Date de publication : 1 mars 2014

Pagination : 161-162

ISBN : 978-2200929107

ISSN : 0035-1423

Référence électronique

Giacomo Losito, «Daniela Sarasella, Cattolici a sinistra. Dal modernismo ai giorni nostri », Revue de I'histoire des religions [En ligne], 1 | 2014, mis en ligne le 13 mai 2014, consulté le 22 septembre 2020. URL : http://journals.openedition.org/rhr/8236 ; DOI : https://doi.org/10.4000/rhr.8236

Ce document a été généré automatiquement le 22 septembre 2020.

Tous droits réservés 


\title{
Daniela Sarasella, Cattolici a sinistra. Dal modernismo ai giorni nostri
}

\author{
Rome-Bari, Laterza (« Quadrante Laterza », 178), 2011
}

Giacomo Losito

\section{RÉFÉRENCE}

Daniela Sarasella, Cattolici a sinistra. Dal modernismo ai giorni nostri, Rome-Bari, Laterza (« Quadrante Laterza », 178), 2011, 285 p., 21 cm, 22 €, ISBN 978-88-420-9785-3.

$1 \quad 178^{e}$ volume de la prestigieuse collection «Quadrante Laterza ", l'ouvrage signé par Daniela Saresella, titulaire de la chaire d'Histoire contemporaine de la Faculté de Sciences politiques de l'Université de Milan, présente un panorama très complet du complexe monde politico-culturel transalpin qui, dès la fin du xix siècle et jusqu'à nos jours, a conjugué son appartenance au catholicisme et une ouverture, voire parfois une vraie militance, avec les partis et mouvements de la gauche italienne. L'auteure montre l'impossibilité de réduire la variété des sensibilités et des positions sous l'étiquette par trop simpliste d'un "catholicisme progressiste" qui n'aurait fait que préparer la Théologie de la libération même si évidemment, comme elle le remarque, les sympathisants de cette dernière n'ont pas non plus manqué en Italie. Certainement c'est cette variété, le foisonnement des initiatives, des options et des programmes, souvent alternatifs, parfois conflictuels, qui frappera le lecteur ne connaissant pas ou connaissant mal l'univers humain et intellectuel ici décrit.

Quatre chapitres présentent, suivant un ordre chronologique, d'abord les premiers contacts entre catholiques et socialistes, avant la Grande Guerre, puis la commune lutte antifasciste, jusqu'à la Résistance (ch.I) ; ensuite, durant la deuxième après-guerre, l'effort conduit, contre les directives de la hiérarchie vaticane, pour élargir progressivement les bases du consensus démocratique républicain, jusqu'à inclure les socialistes, et aboutissant en 1994 à la fin du parti unique des catholiques, la Démocratie chrétienne (ch. II et III); enfin la participation, elle aussi plutôt 
contrecarrée par les plus hautes autorités ecclésiastiques du pays, aux agitées et souvent malheureuses coalitions anti-berlusconiennes (ch. IV). Sans doute ce monde bigarré n'a-t-il pas compté les personnalités les plus connues de la vie politique italienne au $\mathrm{xx}^{\mathrm{e}}$ siècle, mais en sont issues des figures comme Giuseppe Dossetti, dont il faut rappeler l'influence à l'Assemblée constituante en 1946-47 puis auprès du Concile Vatican II ; Aldo Moro, le chef de la Démocratie chrétienne victime du terrorisme des brigades rouges (dont plusieurs membres étaient passés par le militantisme catholique), qui poussa son parti aux alliances avec les socialistes et les communistes; et plus récemment Romano Prodi, le seul responsable politique ayant réussi à enfreindre à deux reprises l'hégémonie berlusconienne durant les vingt dernières années.

3 L'importance du modernisme pour cette famille d'esprits, soulignée dans le sous-titre, apparaît dans le rôle joué par Romolo Murri, fondateur de la première démocratie chrétienne en Italie, ou par Ernesto Buonaiuti, maître à penser d'intellectuels démocrates qui auront les options politiques les plus variées; mais aussi par la personnalité de ceux qui vont être les trois premiers historiens italiens du modernisme, Michele Ranchetti et le prêtre résistant Lorenzo Bedeschi, tous deux protagonistes du dialogue avec les socialistes et les communistes, ainsi que Pietro Scoppola, l'un des rares intellectuels démocrates-chrétiens à avoir défié publiquement les directives des autorités vaticanes en matière de morale familiale, aussi fortement impliqué dans l'opposition à Silvio Berlusconi.

4 En prolongement de cette remarquable synthèse, l'index des noms et l'ample bibliographie que l'on pourra découvrir dans le riche appareil de notes permettent d'approfondir la connaissance de la vaste galaxie des « catholiques de gauche » italiens.

\section{AUTEURS}

\section{GIACOMO LOSITO}

Archives Maurice Blondel, Louvain-la-Neuve 